\section{PROGRESS IN COSMOLOGY}

\section{Cosmology}

By H. Bondi. (Cambridge Monographs on Physics.) Pp. ix +179 . (Cambridge: At the University Press, 1952.) 22s. 6d. net.

$\mathbf{N}$ his presidential address to Section A (Mathe1 matics and Physics) of the British Association in 1888, G. F. FitzGerald suggested that "a successor in this chair might well devote himself to a review of the cosmical theories propounded within the last few years". He added, "The opportunities for piquant criticism would be splendid". Since there seems never to be lacking a supply of these theories produced "within the last few years", there is naturally not lacking a number of men of science still sharing FitzGerald's attitude towards them.

Criticism there must, of course, be. But the important thing is that general progress is being made in the study of the large-scale problems of the physical universe. Observational evidence is accumulating.; this in itself is almost inevitable, but there is also progress in appreciating its relevance and significance from a general physical point of view apart from highly specific theories. On the side of the theories themselves, much has been learned that could be discovered only by the actual working out of the results of their attempted application to the cosmological problem; each serious new theory seeks to overcome the difficulties encountered by its predecessors. In the course of the work, much has been learned, too, about various general physical theories as such, apart from this particular application. Some theorists would claim that fundamental insight has been gained into the origin of laws of Nature. Above all, the main problems to be solved in cosmology are becoming more and more clearly formulated; and, though the theories differ greatly in their ways of getting results, when due regard is paid to the features common to the results themselves, definite progress towards the solution of some of these problems can undoubtedly be claimed.

As a masterly account of this whole state of affairs, it is hard to imagine anything that could be better than Mr. H. Bondi's book. By the exercise of the greatest skill in marshalling his material and of the utmost clarity of expression, he succeeds in making his account effectively complete without any sense of undue compression. Also, he does not shirk the exposition of what is essential in the technicality of the work, while always giving primary attention to the concepts involved.

Though scrupulously fair to other theories, Mr. Bondi naturally states his preference for the "steadystate" theory of cosmology, with its concomitant hypothesis of the continual creation of matter. This theory was originated by him and $\mathrm{T}$. Gold in 1948 . They did not claim that it must be correct, but $\mathbf{M r}$. Bondi points out the extreme epistemological difficulty in the way of any fundamental progress if it is found to be false. Actually, it does seem to give a better account of the large-scale behaviour of the universe than does any previous theory. However, it encounters the obvious trouble that the universe does not conform strictly to the "perfect cosmological principle", from which the theory is derived, though there is no evidence that it does not conform statistically. F. Hoyle's alternative approach, originally published about the same time, is more satisfactory from this point of view, but Hoyle was not so concerned to deal with the epistemological situation. All this is clearly explained in the book.

It seems to me that the relationship between the procedures of Bondi and Gold and of Hoyle indicates the way in which further progress may be expected. They illustrate the "deductive" and "extrapolating" procedures so well distinguished by Mr. Bondi (p. 5). Whereas in the past this distinction has been illrecognized and has resulted in fruitless controversy, we now have an instance of the procedures tending to consistency. A fundamental examination of the conditions for consistency of the two types of procedure is required and may yield the next advance.

\section{W. H. MCCreA}

\section{AMPHIBIANS OF WESTERN NORTH AMERICA}

\section{Amphibians of Western North America}

By Robert C. Stebbins. Pp. xvii +539 (64 plates) (Berkeley and Los Angeles : University of California Press ; London : Cambridge University Press, 1951.) $56 s .6 d$. net.

$T^{T}$ is refreshing to find an author who makes no 1 pretensions to writing for the benefit of some section of his fellow men, but says with simplicity, "I have put into the volume what I have wanted to know ...". The result reveals Mr. R. C. Stebbins as a naturalist, and for anyone who, like him, wants to know not only what amphibians occur in western North America but also, and above all, how and under what conditions they live, the book provides a great many answers; it also provides a wealth of comparative information for others of similar bent but concerned more directly with other geographical regions.

As a member of the staff of the Museum of Vertebrate Zoology of the University of California, the author is an experienced taxonomist, and the framework of the book is the taxonomic arrangement of the animals. There are keys, accompanied by explanatory diagrams, for the identification of the animals both as adults and larvæ. Species and subspecies are described and figured, and their general and local distribution indicated and mapped. Then, for each form, there are extensive notes on its behaviour, habitat, food, reproduction and so forth. These notes are based on the author's personal observations or are taken from impeccable sources, many of them hitherto unpublished. Twelve plates show typical habitats, and there is a glossary of technical terms as well as an index.

No book of this kind can satisfy everybody. Those whose interests are mainly ecological will doubtless regret the absence of physical data relating to the different types of habitat, information regarding predators, parasites and so on. Others, more taxonomically inclined, will wish that more had been said about the very interesting phenomenon shown by the salamander Ensatina eschscholtzi, where the end-terms of two subspecies chains, deriving from a common stem, meet and behave as distinct species; that more, too, had been said about the discontinuous distribution of Ambystoma tigrinum and its causes; and that genera and subgenera had been less capriciously treated. But apart from such matters of scope and emphasis, there are few serious defects for criticism. The segregation of the illustrations of the larvæ and of the distributional maps away from the 